\title{
Breve, brevíssimo! O discurso cinematográfico brasileiro dos anos 1960 em sua veiculação externa
}

Paula Regina Siega

UESC

\begin{abstract}
Resumo
O artigo aqui apresentado se constrói com base nos ensaios breves produzidos pelos autores do Cinema Novo durante a década de 1960 e publicados na Itália, no mesmo período. O propósito é trazer à luz textos desconhecidos no Brasil, mas que colaboraram para a circulação do imaginário brasileiro fora das fronteiras nacionais, em um momento de desprovincialização da nossa cultura. Forma congenial ao movimento, o ensaio breve foi praticado pelos cineastas para fornecer ao público europeu as chaves de leitura das obras cinematográficas que estavam criando. Documentando as transformações das poéticas dos autores, os textos revelam como a literatura brasileira serviu de paradigma à estética cinemanovista, suprindo assim a lacuna oferecida por uma incipiente tradição cinematográfica. Observando o quanto conceitos quais "nacional”, "colonial”, "universal” ou "identidade" estiveram ao centro das reflexões intelectuais do movimento, o trabalho mostra que, após o golpe de 1964, a utopia revolucionária foi substituída pelo sentimento trágico da política. A este sentimento ligou-se o ideário antropofágico do movimento tropicalista que, na sua vertente cinematográfica, expressou com a fórmula "canibalismo dos fracos" o processo autodestruidor de um Brasil que devorava a si mesmo.
\end{abstract}

Palavras-chave: Cinema Novo; ensaio breve; literatura; colonialismo; antropofagia.

\section{Riassunto}

L'articolo qui presentato è costruito basandosi sui testi prodotti dagli autori del Cinema Novo durante il decennio del 1960 e pubblicati in Italia, nello stesso periodo. Il proposito è portare alla luce testi sconosciuti in Brasile, ma che hanno collaborato per la circolazione dell'immaginario brasiliano oltre le frontiere nazionali, in un momento di sprovincializzazione della nostra cultura. Forma connaturale al movimento, il saggio breve è stato praticato dai cineasti per fornire al pubblico europeo le chiavi di lettura delle loro creazioni cinematografiche. Documentando le trasformazioni delle poetiche degli autori, i testi rivelano che la letteratura brasiliana ha assunto il ruolo di paradigma per la estetica cinemanovista, colmando in questo modo la lacuna offerta da una incipiente tradizione cinematografica. Osservando come concetti quali "nazionale", "coloniale", "universale" o "identità" stessero al centro delle riflessioni intellettuali del movimento, il lavoro dimostra che, dopo il colpo di Stato del 1964, l'utopia rivoluzionaria è stata sostituita dal sentimento tragico della politica. A questo sentimento si legò l'idea tropicalista dell'antropofagia che, nella sua corrente cinematografica, ha espresso con la formula "cannibalismo dei deboli" il processo autodistruttivo di un Brasile che divorava se stesso.

Parole chiave: Cinema Novo; saggio breve; letteratura; colonialismo; antropofagia. 
1. DAHL, Gustavo;

SARACENI, Paulo Cesar.

"Cinema Novo e estruturas econômicas tradicionais", 1967 , p. 431.

2. Ibidem.

\section{Filmes e falas em circulação}

Com a eclosão do Cinema Novo durante a década de 1960, a cultura brasileira conheceu um período de relativa projeção externa, sendo representada contemporaneamente por obras cinematográficas que se esforçavam em retratar o país com uma linguagem de caráter nacional, e por um discurso crítico interessado em fornecer as bases teóricas daquela linguagem. Fora de nossas fronteiras, os filmes e as falas dos cineastas faziam com que o público estrangeiro, sobretudo europeu, fosse instigado pela hipótese de que o cenário político e econômico mundial viesse a ser objeto de uma revolução cultural oriunda do terceiro mundo. Enquanto obras quais Deus e o diabo na terra do sol, Os fuzis ou $O$ dragão da maldade contra o santo guerreiro pareciam ser a confirmação estética da tese, os discursos pronunciados e escritos por autores do movimento realizavam um amplo trabalho de divulgação, defesa e legitimação teórica do que vinha sendo praticado artisticamente. Além de debates, colóquios e mesas redondas, o veículo privilegiado para a circulação do discurso cinemanovista foram as revistas especializadas de cinema, onde assumiram três formas principais: a declaração, a entrevista e o ensaio breve.

A propensão dos cineastas a esse tipo de produção textual pode ser explicada pelo fato de, antes de se dedicarem à realização de filmes, terem participado da atividade cineclubista, base de uma formação cinematográfica que, passando pela crítica, conduzia à atuação como roteiristas, produtores, montadores ou diretores dos próprios filmes. Como pontuaram Gustavo Dahl e Paulo Cesar Saraceni em um dos muitos ensaios breves brasileiros que circularam então na Europa, foi no período em que "a 'nouvelle vague' derrubava na França as barreiras existentes entre o amador de cinema e o fazedor de cinema, entre o crítico e o realizador", que a geração do Cinema Novo saía dos "limites da crítica e do cine-clubismo" para "ingressar no campo da realização" ". A importância da palavra escrita ou falada como elemento integrante das ações de divulgação é visível no trecho abaixo:

Começando por articular os grupos existentes na Bahía, no Rio e em São Paulo, foram usados todos os meios disponíveis - jornais, suplementos literários, revistas, cineclubes e cinematecas - para prestigiar um "cinema novo" brasileiro, que até então era uma virtualidade. ${ }^{2}$

Para os jovens intelectuais, o ingresso no campo da realização cinematográfica significava considerar não apenas os aspectos da produção, mas também os problemas e alternati- 
vas à circulação no fechado mercado nacional, dominado pelo produto estrangeiro (filmes americanos e europeus), de um lado, e pelo que consideravam o produto nacional de "baixa qualidade” (as execradas chanchadas), do outro. Se a produção independente era a chave para realizar filmes nos quais a poética do autor não devesse dobrar-se aos compromissos com o capital, a saída para furar as barreiras mercadológicas era penetrar no mercado externo, conquistando atenção e prestígio internacionais para então ser aceitos pelos distribuidores e público internos, acostumados a aceitar sem reservas o que já tivesse sido aprovado no exterior.

Conduzidas com relativo sucesso, as estratégias produtivas e distributivas do Cinema Novo no início dos anos 1960 são relatadas por Arnaldo Carrilho, então adido cultural do Brasil em Roma. Em virtude do "enorme coeficiente de provincianismo que faz com que [o público] aceite passivamente o produto estrangeiro em detrimento do nacional”, é necessária a atuação de um agente externo, capaz de indicar ao público a qualidade dos filmes ao qual estão assistindo e, por isso, "o que se verifica é a função publicitária dos Festivais Internacionais de cinema, cujos pareceres finais agem no Brasil como elemento seguro de sucesso comercial da fita"3.

Os esforços de expansão externa foram delineados também por Dahl e Saraceni: era conquistando a atenção nos festivais internacionais, explicavam eles, que se apresentavam as possibilidades de "fazer ruir as velhas estruturas do cinema nacional", aproveitando "o tradicional complexo de inferioridade brasileiro" para "liquidar de fora para dentro os vícios artísticos, culturais e econômicos do nosso cinema"4.

\section{A marca cruel do subdesenvolvimento}

As colocações a respeito do "complexo de inferioridade" brasileiro estavam em sintonia com o sentimento de recusa do público comum e do cinéfilo culto em relação à produção nacional. Para a consciência deste sentimento colaborou de forma basilar Paulo Emilio Salles Gomes, em ensaio breve que produziu grande impacto sobre os realizadores e pensadores do cinema brasileiro. Apresentado na Primeira Convenção Nacional de Crítica Cinematográfica, realizada em São Paulo (1960), e publicado no suplemento literário do Estado de São Paulo com o título "Uma situação colonial?", o texto abordava a questão da inadequação do cinema brasileiro em relação às expectativas nacionais, formadas a partir de um modelo externo.
3. CARRILHO, Arnaldo.

"Técnicas de trabalho e estrutura econômica do Cinema Novo", 1967, p. 426-427.

4. DAHL, Gustavo; SARACENI, Paulo Cesar. "Cinema Novo e estruturas econômicas tradicionais", 1967 , p. 431. 
5. GOMES, Paulo Emílio Salles. "Uma situação colonial?". Revista Contracampo, 2000.

6. Ibidem.

7. GALVÃO, Maria Rita. Burguesia e Cinema: O Caso Vera Crur, 1981, p. 28.
Para Salles Gomes, todos os agentes do sistema cinematográfico brasileiro (produtivos, artísticos, distribuidores, consumidores e críticos) viviam um estatuto colonial determinado pelo domínio do produto estrangeiro no mercado, fruto de um mecanismo perverso que fortalecia a percepção coletiva segundo a qual o "cinema de verdade" era somente o que vinha de fora, e ao qual não se subtraía nem mesmo o crítico esclarecido:

Assim como a prosperidade do importador está condicionada a realidades econômicas estrangeiras, o enriquecimento cultural do crítico gira progressivamente na órbita de um mundo cultural distante. [...]. O filme nacional é um elemento perturbador para o mundo, artificial mas coerente, de idéias e sensações cinematográficas que o crítico criou para si próprio. Como para o público ingênuo, o cinema brasileiro também é outra coisa para o intelectual especializado. Atacando com irritação, defendendo para encorajar, ou norteado pela consciência de um dever patriótico, o crítico deixa transparecer sempre o mal-estar que o impregna. Todas essas posições, particularmente o sarcasmo demolidor, são véus utilizados para esconder o sentimento mais profundo que o cinema nacional suscita no brasileiro bem formado - a humilhação. ${ }^{5}$

Salles Gomes denunciava o fato de a nossa cultura cinematográfica - realizada em termos que nos alienavam econômica e culturalmente do que era nosso - produzir uma perene sensação de frustração diante do resultado obtido pelos esforços aventureiros da indústria local. Sobre a nossa experiência estética vigia então uma demarcação de inferioridade que nos diferenciava dos modelos artísticos produzidos pelas nações industrialmente avançadas:

\section{A indústria, as cinematecas, o comércio, os clubes de cine- ma, a crítica, a legislação, os quadros técnicos e artísticos, o público e tudo o mais que eventualmente não esteja incluído nesta enumeração, mas que se relacione com o cinema no Brasil, apresentam a marca cruel do subde- senvolvimento. ${ }^{6}$}

Sem conseguirem se subtrair à dinâmica colonial que os fazia espectadores da produção alheia, os intelectuais brasileiros adotaram o cinema internacional (europeu ou estadunidense) como paradigma de uma universalidade acessível ao consumo, mas impensável para os rudimentares padrões da indústria nacional. Por isso durante muito tempo, observou Maria Rita Galvão, "pensar cinema no Brasil significou pensar cinema estrangeiro". ${ }^{7}$ A fórmula era praticamente a mesma também para as plateias: "Para o público brasileiro, cinema é cinema estrangeiro”, afirmava Jean Claude Bernardet em 1967, explicando como os espectadores não encontrassem na produção nacio- 
nal o que estavam acostumados a ver nos filmes estrangeiros, sobretudo westerns e comédias americanas ${ }^{8}$. Razão pela qual, observava por sua vez o cineasta David Neves, em 1965:

Titubeante, na verdade, tem sido o espectador brasileiro que não se entrega facilmente, que reage, que perde a seiva de um mundo novo, em busca de contactos, de relações de ressonância com uma concepção provinciana e alienada que traz consigo.

- O cinema brasileiro só mostra miséria...9

A tentativa cinemanovista era vencer essa resistência através da conquista do espectador externo. Para tanto, o passo dado foi grande: conscientes da impossibilidade de atingir para o cinema nacional o padrão industrial das grandes economias, os cineastas deixaram de encará-lo como fator necessário à expressão cinematográfica, e passaram a ver na pobreza de recursos a base da própria linguagem, considerada representação "autêntica" do Brasil e de suas mazelas. Agindo dessa forma, libertavam-se do sentimento de inferioridade diante da cinematografia mundial, certos de serem, ao par dos colegas de cinematografias mais imponentes, detentores de uma legítima poética, como revelara o arrojado e subdesenvolvido Rio Quarenta Graus, de Nelson Pereira dos Santos:

Defeituoso, maladroit, eis a chave mestra para se classificar formalmente o seu mundo e o que lhe seguirá. [...] Num determinado momento, a ousadia máxima para um filme pobre e de conceitos pobres a respeito de produção: a grua improvisada que termina por trucagem numa maquete de visão-tipo do Rio: o Pão de Açucar e a Baía de Guanabara. Nelson Pereira dos Santos, usando recursos de todo um cinema que o precedeu, traça as bases de uma nova escola: a da autenticidade. ${ }^{10}$

\section{Eruditos e populares}

Embora os filmes do Cinema Novo estivessem sendo projetados desde 1960 na França, Espanha, Portugal, Alemanha e URSS, foi sobretudo na Itália, com a Quinta Resenha do Cinema Latino-Americano realizada em Gênova, de 21 a 30 de janeiro de 1965, que eles começaram a ser reconhecidos como parte de um movimento coletivo. Sob a direção de Floris Luigi Ammannati, a Quinta Resenha dedicou um espaço especial ao Cinema Novo, apresentando uma retrospectiva das suas obras, premiando Vidas Secas e Os fuzis, e realizando uma mesa re-
8. BERNARDET, Jean-Claude. Brasil em tempo de cinema, 1967, p. 14.

9. NEVES, David. "Poética do Cinema Novo", 1967, p. 422.

10. Ibidem. 
11. VIGANÒ, Aldo. "Discorso di Aldo Viganò”, 1967, p. 409.

12. ROCHA, Glauber. "Cinema Novo e cinema mondiale", 1965 , p. 435-436.

13. Idem. "L'estetica della violenza". Rivista Cinema 60, 1965.

14. Idem. "Eztetyka da fome 65", 2004, p. 63-67. donda sobre o movimento. Definindo o Cinema Novo como "una delle più significative correnti culturali" da América Latina e "fenomeno unico nella storia del cinema mondiale", o organizador do debate, Aldo Viganò, pontuava o fato de que "le opere dei giovani registi brasiliani" eram "presentate per la prima volta in un contesto organico e completo". ${ }^{11}$ Deste modo, ofereceu-se ao público uma visão unitária das obras e dos programas dos autores, que ganharam repercussão também fora da Itália.

Da mesa redonda participaram Antonio Candido, Arnaldo Carrilho, David Neves, Paulo Cesar Saraceni, Gustavo Dahl, Carlos Diegues e Glauber Rocha. As contribuições dos debatedores foram publicadas em 1967, nos anais do congresso Terzo mondo e comunità mondiale. Dos ensaios apresentados, ganhou inaudita projeção o de Glauber, que, tendo como título original "Cinema Novo e cinema mondiale" 12 , foi referido e publicado imediatamente pela imprensa italiana como "L'estetica della violenza"13. Em junho de 1965, apareceu também na revista Civilização Brasileira em versão ampliada e modificada, sob o título "Uma estética da fome"14. A aguerrida fala do cinemanovista desenhava o compromisso da sua geração em realizar um cinema empenhado não só com a realidade brasileira, mas também com a da América Latina. A partir de uma impostação marcadamente anticolonial, o discurso sublinhava a distância entre as sociedades ditas avançadas e o mundo subdesenvolvido, acusando as primeiras de interessar-se pelo segundo somente na medida em que isso satisfazia a sua nostalgia do primitivo. De grande efeito sobre o público reunido no evento, a tese reverberou na crítica especializada europeia, tornando-se uma referência obrigatória para os teóricos que a partir daí se interessassem pelo cinema brasileiro ou latino-americano.

Não tendo conquistado a celebridade do brevíssimo ensaio de Glauber, os demais textos oferecem muitos elementos para a compreensão não só da trajetória do Cinema Novo, como da importância de conceitos quais "nacional”, "popular”, "colonial”, "original” e "universal”, então ao centro das reflexões a respeito da cultura brasileira e do cinema que se propunha a representá-la. Para os fins dessa análise, interessa apontar para a importância que a literatura vem a recobrir no discurso cinemanovista que, na ausência de uma tradição cinematográfica nacional, a ela recorreu para fixar um antecedente histórico-cultural para o movimento. São constantemente ultrapassadas as linhas de demarcação entre literatura e cinema, em falas que estabelecem uma espécie de equivalência entre linguagem fílmica e literária. Observe-se, por exemplo, essa passagem do discurso de David Neves: "Cinema é antes prosa do que verso, mas que melhor poeta do que Guimarães Rosa, devia pensar Glauber Rocha, dirigindo o roteiro de Deus 
e o Diabo na Terra do Sol? Que afinidade sutil entre o jovem baiano e o grande escritor" ${ }^{\prime 1}$.

A adoção da obra monumental de Guimarães Rosa como referencial para o cinema rocheano, mais do que indicar a semelhança das leituras do Brasil feitas pelo escritor e pelo cineasta, aponta para a ausência, no panorama cultural brasileiro, de um modelo cinematográfico da mesma grandeza. Já Alex Viany, em ensaio publicado na revista italiana de cinema Bianco e Nero, em 1964, havia explicitado a lacuna cinematográfica em termos do que então se entendia por "cultura nacional":

\begin{abstract}
È indubbio che, dal punto di vista di una cultura brasiliana, noi non abbiamo un cinema nazionale. Abbiamo, questo è vero, sparsi in alcuni film validi, o almeno parzialmente validi, gli elementi di un cinema veramente brasiliano - così come si parla, ad esempio, di una letteratura brasiliana. ${ }^{16}$
\end{abstract}

Viany justificava a falta de um "autêntico" cinema brasileiro como uma decorrência da estrutura econômica do subdesenvolvimento, pois o cinema, "come espressione di una cultura nazionale", explicava, existia somente nos países industrialmente progredidos. O domínio econômico de tais países era apontado então como imposição cultural percebida como invasão:

Ricordiamo che qui in Brasile - quando già nel nostro secolo la cultura si costituiva realmente in entità nazionale - i grandi mezzi di diffusione dell'era tecnologica [...] capaci di favorire il contatto fra popolo e cultura, furono in realtà i veicoli di una nuova invasione di elementi culturali e subculturali stranieri. ${ }^{17}$

A influência do pensamento de Sales Gomes se faz visível neste outro trecho:

In realtà, come spettatori costretti a una lunga dieta straniera, abbiamo una specie di falso "deposito folcloristico internazionale" in testa; e quando ci sediamo per scrivere un soggetto cinematografico inevitabilmente ricorriamo a queste reminescenza che ci si impongono come realtà che ci circonda, mentre è comodo sovrapporre, coscientemente o no, modelli e stereotipi acquisiti attraverso la saturazione di film stranieri alla realtà brasiliana che ci proponiamo mostrare. $^{18}$

Diante da incipiência do cinema nacional, considerado como modelo a ser superado, o Cinema Novo vinha a estabelecer vínculos com a literatura brasileira - que já havia conquistado um caráter de representatividade nacional -, deitando
15. NEVES, David. "Poética do Cinema Novo”, 1967, p. 422.

16. VIANY, Alex. "Cinema

brasiliano ieri e oggi”. Rivista

Bianco e Nero, 1964.

17. Ibidem, p. 24.

18. Ibidem, p. 28. 
19. Em português no original.

\section{DIEGUES, Carlos.}

"Rapporto dialettico, cinema e cultura in Brasile", 1967, p. 419. nela aquelas que considerava as próprias raízes. Observe-se que criação de uma genealogia literária para o cinema não era uma operação inédita, tendo já sido efetuada no início do século pelos ensaios de Sergei Eisenstein, autor de grande influência na estética e na escrita cinemanovistas, sobretudo de Glauber Rocha.

$\mathrm{Na}$ produção discursiva do movimento, são vários os textos que apontam para a ruptura com o cinema nacional - excetuando a poética de Humberto Mauro - e, em contrapartida, para o estabelecimento de uma continuidade com a literatura do país. A importância dessa literatura vinha a ser considerada tanto em função de uma tomada de posição política frente à realidade, como do seu papel no estabelecimento de uma identidade nacional, a mesma que os autores propunham-se a encontrar para o cinema através de uma linguagem brasileira. Em Gênova, é a busca e encontro dessa linguagem que a "estética da fome" tematizava: a cultura do subdesenvolvimento não poderia ser representada com os recursos tecnológicos e linguísticos da cultura dita "avançada", mas deveria encontrar na própria exasperante realidade, na própria deficiência de meios, os temas e formas com os quais expressar-se, superando o estágio de dependência.

Enquanto Glauber teorizava sobre a estética da fome/violência, Diegues discursava sobre a dialética entre as culturas erudita e popular brasileiras que, supostamente, encontravam no Cinema Novo a sua síntese. Indicando a influência dos pensadores do cinema mundial sobre a formação filosófica do cineasta brasileiro, Diegues observava a contradição entre essa formação "universal" e a carência de uma tradição cinematográfica nacional. Assim, era na literatura que o cinemanovista encontrava os precedentes brasileiros para a linguagem que vinha sendo construída pelo cinema:

In rapporto alla cultura erudita brasiliana, troviamo nei più significativi artisti posteriori al movimento modernista, alcuni elementi che hanno servito di base al "cinema novo" $\left[{ }^{19}\right]$.

Molto vicini all'idea di un "modo di dire cinematograficamente le cose del Brasile" sono Mario e Oswald de Andrade: una nuova lingua brasiliana parlata agli angoli delle strade e dei paesi, tanto diversa da quella dei salotti e dei discorsi ufficiali. ${ }^{20}$

De maneira semelhante ao que Glauber Rocha fizera em alguns dos textos da sua Revisão crítica do cinema brasileiro, Diegues relacionava diretamente a produção cinemato-gráfica à literária, vendo em uma e outra equivalências na tentativa de construção da identidade cultural brasileira. Se "Macunaíma è per la letteratura brasiliana quello che probabilmente 'Barra- 
vento' sarà per il cinema”, a intenção cinematográfica em descrever o "sforzo di una civiltà che vuole pensare per sé e avere i propri miti ed eroi" se reencontrava também "in Guimarães Rosa, o Graciliano Ramos, João Cabral de Mello Neto o Villa Lobos". Mas se os escritores, em geral, limitaram-se a servir-se da cultura popular para criar um novo estilo literário, com o Cinema Novo se chegava a um período "in cui i miti popolari e le tradizioni erudite si integrano e quelli non saranno più soltanto elemento di stile per queste" 21 . E se o recente golpe de estado modificara o contexto produtivo brasileiro, isso não significava o fim do movimento, pois "La tradizione ci dice che gli intel-lettuali che hanno avuto una presa di coscienza a partire dal 1930, si sono abituati a incorporare ogni fatto nuovo alla loro espressione in una prospettiva dinamica e trasforma-trice"22.

\section{Canibalismo dos fracos e sentimento trágico}

No fim dos anos 60, a ação coletiva e os sistemas cooperativos de produção e distribuição que tinham caracterizado a atividade do Cinema Novo começavam a escassear, e as divisões e desentendimentos dentro do grupo aumentavam ${ }^{23}$. Às crises ideológicas e criativas devido ao momento político, vinha a juntar-se uma crescente intervenção estatal e uma conjuntura econômica desfavorável, com as pequenas produtoras ligadas ao movimento sendo obrigadas a fazer frente ao Instituto Nacional do Cinema (INC), fundado pelo regime militar ${ }^{24}$. Apesar do instituto inspirar-se no sucesso externo obtido pelo Cinema Novo, os financiamentos estatais eram vistos com desconfiança pelos cinemanovistas, receosos de uma versão comercial do movimento através de filmes que, aproveitando somente algumas de suas características superficiais, não compartilhassem de seus posicionamentos estéticos e ideológicos ${ }^{25}$. Assim, descreve Alexandre Figueirôa, a fase vivida a partir de 1967,

iria revelar que o cinema brasileiro estava dividido entre aqueles que procuravam permanecer fiéis aos princípios do Cinema Novo e prosseguir o trabalho de distribuição iniciado pela Difilm e aqueles que se juntaram às iniciativas do INC. ${ }^{26}$

Entre os que optaram pelos financiamentos do INC estavam os representantes da nova onda do cinema underground, que, embora tivessem sido ajudados pela Difilm (cooperativa
21. Ibidem, p. 420.

22. Ibidem.

23. DIEGUES, Carlos. Cinema

Brasileiro: idéias e imagens, 1999.

24. SALEM, Helena. Nelson

Pereira dos Santos: El sueño possible del cine brasileño, 1997.

25. FIGUEIRÔA, Alexandre. Cinema Novo: $A$ onda do jovem cinema e sua recepsão na Fransa, 2004.

26. Ibidem, p. 28. 


\section{Ibidem.}

28. DIEGUES, Carlos. Cinema Brasileiro: Idéias e imagens, 1999 , p. 22.

29. Sobre a ascendência do filme para o movimento tropicalista, Caetano Veloso escreve em 1970, em carta a Glauber Rocha: "o cinema dele [Rogério Sganzerla] é parente de nossas músicas, de Brasil ano 2000, de Macunaima, de Roda viva - e tudo isso é filho de Terra em transe [...] Terra em transe decidiu o meu 'tropicalismo"'. VELOSO, Caetano. "Carta a Glauber Rocha, Londres, setembro 1970", 1997, p. 377. de distribuição fundada pelos cinemanovistas em 1965), passaram a atacar o Cinema Novo, considerando-o ultrapassado ${ }^{27}$. $\mathrm{Na}$ nova conjuntura, o grupo passava a viver uma situação de impasse, perdendo o caráter programático que caracterizara a "política dos autores" na sua primeira fase. O fim da década de 60 coincidia então com o fim do movimento, rememorado, em 1973, por Carlos Diegues:

Apertado à direita e à esquerda, em dúvida quanto à sua própria validade, chocado com os acontecimentos que não controla, o Cinema Novo começa a decretar a sua própria morte, assinando o óbito preenchido pelas novas gerações.

Acho que fui o primeiro a falar disso, numa entrevista aos Cahiers du Cinéma, em fins de 69 [...]. Quase ao mesmo tempo, Gustavo Dahl e Glauber Rocha anunciam a mesma coisa, no Brasil. ${ }^{28}$

O fronte da recepção italiana, todavia, vivia uma apreciação tardia do Cinema Novo, com Deus e o diabo na terra do sol e Os fuzis sendo projetados no circuito comercial, em 1969. No mesmo ano, a politizada Ombre Rosse publicava um dossiê sobre o movimento, recuperando alguns de seus temas marcantes e delineando a guinada tropicalista do final da década. O dossiê era composto por textos de críticos italianos, por uma entrevista com Ruy Guerra, e por ensaios de breve ou brevíssima extensão assinados por Carlos Diegues, Gustavo Dahl e Joaquim Pedro de Andrade. Da mesma forma em que, em 1965, os cineastas forneceram ao público europeu os subsídios para o entendimento dos filmes cinemanovistas a partir de uma tradição intelectual nacional, os novos discursos apresentam as bases teóricas do que se estava experimentando.

Antes, filmes em branco e preto tinham veiculado uma linguagem visual enxuta e exasperada, com uma forte adesão ao real (a luz ofuscante do sol, a paisagem árida, o latifúndio, a fome e a miséria das zonas rurais) que tinha sido sintetizada pela trilogia do sertão (Vidas secas, Deus e o diabo na terra do sol e Os fuzis). Essa linguagem pouco apresentava em comum com a ambiguidade das obras que vinham sendo produzidos no Brasil a partir do golpe. O contexto político brasileiro tinha sido radicalmente modificado, demonstrando a impossibilidade da revolução popular para a qual apontavam filmes quais Os fuzis, Deus e o diabo ou Ganga Zumba.

Em 1967, Glauber Rocha tinha demonstrado, com Terra em transe, a necessidade de uma nova estética para expressar aquela outra contingência histórica, abrindo caminho para o tropicalismo, movimento fortemente influenciado pelo modernismo $^{29}$. Se os filmes sobre o sertão encontraram inspiração sobretudo no realismo regionalista, as novas produções volta- 
vam-se ao modernismo, à Semana da Arte Moderna de 1922 e à teoria antropofágica de Oswald de Andrade.

Tratava-se de uma nova maneira de propor-se diante da realidade brasileira, que se refletia em novos modos de expressá-la, marcados pela coexistência de elementos modernos e arcaicos, pela exuberância de cores e de formas, pela presença do humor, da alegoria, além das constantes referências ao ato de devorar o outro. Dada a grande diferença em relação ao estilo e temática dos filmes anteriores, os cineastas tiveram que justificar, teoricamente, a mudança de prisma, fornecendo ao público europeu um conjunto de referências artísticas que permitissem compreender as inovações linguísticas de filmes quais Azyllo muito louco, Macunaíma e Brasil ano 2000, entre outros. A nova filmografia podia assim ser enquadrada em um mais amplo contexto cultural, do qual continuavam a fazer parte renomados intelectuais. Era necessário, além disso, explicitar o caráter político que o movimento tentava manter, como fazia Carlos Diegues no seu ensaio, evidenciando o quanto a antropofagia estivesse ao centro das novas reflexões teóricas:

In Brasile le basi di questa nuova cultura militante sono state gettate per la prima volta dal movimento modernista del 1922. Di qui sono venuti fuori Oswald de Andrade, Villa Lobos, Mario de Andrade, Jorge de Lima, ecc. [...]. Era necessario fare dell'antropofagia un sistema, della disorganizzazione un metodo, del disordine un'organizzazione. Come tutte le antropofagie anche la nostra ha due movimenti: distrugge quello che è divorato e nutre colui che divora. Ma è stato il Cinema Nôvo in concomitanza con il teatro e la nuova musica, ad introdurre in questo concetto di cultura nazionale il sentimento politico. ${ }^{30}$

A colocação da política no âmbito do "sentimento" e não da "consciência" evidencia como essa política, após o golpe, passou a ser percebida a partir de um verdadeiro "sentimento trágico”, sintoma de um período de crise e desagregação:

La politica non solo come scienza, ma come tragedia quotidiana vissuta nel cuore della sua esistenza da ogni uomo di un paese sottosviluppato. Per noi, la politica non è solo un gioco di cui conosciamo le regole e cui partecipiamo buttando le nostre carte a favore di un giocatore. La politica è la ragione stessa della nostra vita, non per scelta individuale e cosciente, ma perché la respiriamo in ogni strada, in ogni angolo, in ogni piazza dell'America Latina. Noi vogliamo vivere questa tragedia e trasformarla. ${ }^{31}$

Contemporaneamente à percepção dramática do quotidiano nacional, no discurso de Diegues delineava-se um processo criativo e analítico que reconsiderava o valor das comédias musicais para a composição de uma linguagem cinematográfica
30. DIEGUES, Carlos. "Un cinema sempre nuovo". Rivista Ombre Rosse, 1969.

31. Ibidem, [grifo nosso]. 
32. Ibidem, p. 35.

33. DAHL, Gustavo. "Una canaglia in crisi". Rivista Ombre Rosse, 1969.

34. Ibidem.

35. Ibidem, [grifo nosso].

36. ANDRADE, Joaquim Pedro de. "Antropofagia e autofagia". Rivista Ombre Rosse, 1969. [grifo nosso]. de cunho nacional. Recusadas no início da década pelos fautores de um cinema "elevado", as chanchadas eram filtradas agora pela ótica antropofágica, passando a ser consideradas como parte da cultura popular e, como tal, portadoras de uma contribuição criativa: "sono opere brutte, fatte terribilmente male, ma nello stesso tempo hanno un'importanza fonda-mentale nella creazione di una lingua brasiliana nel cinema" ${ }^{32}$.

A dimensão trágica que a política assumia após o golpe se configurava também no discurso de Gustavo Dahl que, ao comentar a figura do intelectual atormentado, o "canaglia in crisi" dos filmes Terra em transe, $O$ desafio e $O$ bravo guerreiro, falava de "un debole che tenta superare tragicamente la sua condizione" ${ }^{33}$. E isso porque a sua geração, explicava ele, "formatasi tra la morte di Getulio Vargas e l'ascesa di Castelo Branco", lançava sobre o Brasil "uno sguardo pessimista”. ${ }^{34} \mathrm{~A}$ perspectiva da morte concreta ou simbólica dominava a visão de mundo dos jovens cineastas, permeada pelo sentimento de autopunição que os filmes comunicavam:

I suoi personaggi, dilacerati fra la coscienza della miseria tricontinentale e della impotenza, dell'impossibilità di superarla, di superarsi, trovano una unica soluzione: il suicidio. Oltre alla forma pura, la soluzione può venire in diversi imballaggi: lotta armata, sesso, amore, fumo, alcool e la meno nobile di tutte, l'alpinismo sociale. Ciascuno si uccide come vuole o come puo..$^{35}$

Já na releitura cinematográfica do modernismo operada por Joaquim Pedro de Andrade, em Macunaíma, o sentimento de desencanto em relação à situação brasileira se manifestava na ideia do "canibalismo dos fracos”, que transformava a prática antropofágica em autofagia, metáfora de um processo de autodestruição:

L'antropofagia diventa istituzionale anche se si dissimula. I nuovi eroi, alla ricerca di una coscienza collettiva, partono per divorare chi fino adesso li ha divorati, ma ancora sono troppo deboli.

La Sinistra, mentre viene divorata dalla Destra, si allena e si purifica attraverso l'autofagia, cannibalismo dei deboli. La Chiesa celebra nelle messe l'antropofagia, ridivorando il Cristo; le vittime e il boia si identificano e si divorano. Tutto - nel cuore come nei denti - è cena.

Nel frattempo, e nel modo più copioso il Brasile divora $i$ brasiliani. Macùnaima è la storia di un brasiliano divorato dal Brasile. ${ }^{36}$

A síntese desse Brasil trágico-carnavalesco que consumia e aniquilava os brasileiros era dada, involuntariamente, por uma 
notícia fornecida pelos relatores da revista que, sob o título Delitto psicologico, falavam do AI-5. Informando que este previa pena de morte e prisão perpétua para criminosos políticos, a revista disponibilizava aos interessados um endereço ao qual pedir cópias do texto do decreto, de modo a divulgar a grave situação vivida no país.

\section{De Getúlio a Castelo, os heróis sem nenhum caráter}

O contexto político brasileiro foi retratado, também, em outro volume monográfico dedicado ao Cinema Novo, em 1969. Na revista Cineforum foram publicados diversos ensaios sobre temáticas que englobavam o movimento, contando com a participação de Eduardo Lourenço e Michel Esteve, entre outros. Dos cinemanovistas, o único presente era Glauber Rocha, com uma republicação de L'estetica della violenza, uma tradução para o italiano do roteiro de Deus e o diabo na terra do sol, e uma apresentação dos filmes Macunaíma e Os herdeiros, que aqui comentamos.

De modo semelhante ao que fizera Carlos Diegues nas páginas da Ombre Rosse, Glauber procurava delinear o quadro histórico e teórico ao qual relacionar os filmes mais recentes, fornecendo uma nova chave de leitura para o Cinema Novo. Além da situação política da nação, eram evidenciados os vínculos do movimento com a tradição intelectual do Brasil (aquela parte da tradição que ele considerava "revolucionária" por colaborar para a formação de uma arte autenticamente nacional).

Como na tese de Gênova, a preocupação do cineasta era expor ao europeu a originalidade da cultura brasileira. Mas se, em 1965, esta era constituída pela sua principal diversidade em relação ao mundo "desenvolvido" - a fome latino-americana agora se tratava de indicar um processo de ruptura intelectual sintetizado pela ideia de antropofagia. O centro irradiador da independência cultural do país era localizado então na semana da arte moderna de 1922. A partir deste enfoque, a constatação da impotência do intelectual colonizado era substituída pela perspectiva liberatória e altamente criativa do nosso modernismo. Elencando nomes de intelectuais da vanguarda artística do país, o cineasta ressaltava neles o esforço de negação do academicismo e mimetismo da nossa produção cultural, voltada a "un'imitazione dell'arte 'classica' europea" ${ }^{37}$. Depois da semana de arte moderna, explicava, nascia "la vera arte brasiliana",
37. ROCHA, Glauber. "Il nuovo cinema brasiliano è tropicalista". Rivista Cineforum, 1969. 
38. Ibidem, p. 464, 466

39. Ibidem, p. 465.

40. Ibidem.

41. Ibidem.

42. Ibidem. à qual se filiava o movimento tropicalista, herdeiro do "spirito antropofago del $1922 " 38$.

Desenhando um quadro geral da evolução da literatura brasileira durante o século XX, Glauber Rocha estabelecia os nexos que ligavam Macunaíma e $O$ rei da vela ao romance nordestino:

Tra la violenza satirica di Mario de Andrade e Oswald de Andrade (che rappresentano anche l'avanguardia estetica) e i manifesti politici di Jorge Amado, Lins do Rêgo e Graciliano Ramos, c'è una identità fondamentale: il Sud (San Paolo) e il Nord (Pernambuco, Bahia) "vomitano" un Brasile complesso che cerca un suo proprio linguaggio. La musica di Villa Lobos ne è la sintesi. ${ }^{39}$

À contextualização desta cultura erudita que cercava de absorver e fazer-se intérprete do seu "povo", seguia-se o esboço da história política do Brasil, da ditadura de Vargas à militar. Uma revisão sintética e elíptica, onde todos os elementos apareciam ligados por uma espécie de continuidade simbiótica. Em uma História feita de golpes de cena e de estado, os "heróis da nossa gente" eram também "heróis sem nenhum caráter", revelando a própria essência de Macunaímas, prontos a transformar-se em seus contrários.

Narrada de forma irônica e pungente, a política brasileira revelava a sua conformação surreal e melodramática, onde os personagens sucediam-se uns aos outros sem conseguir subtrair-se ao vórtice a que pareciam condenados. Em uma espécie de opereta nacional, o herói trágico Getúlio Vargas, ex-ditador que retornava ao poder eleito democraticamente, se suicidava "lasciando in eredità al popolo una lettera rivoluzionaria" ${ }^{40}$ Era a vez então do permissivo Juscelino Kubitscheck, que solicitara aos maiores arquitetos do país a construção de Brasília: "città lunare in mezzo alla jungla", ela era "il punto di incontro tra $i$ tecnici del Sud e i 'candangos' poveri del Nord"41. Kubitscheck era Macunaíma, escrevia Glauber, mas mesmo depois do fim do mandato do presidente o herói de Mário de Andrade continuava no poder: o centro da cena tinha sido ocupado por Jânio Quadros, "uomo politico 'tropicalista' per eccellenza” que condecorara Che Guevara, proibira as mulheres de usarem biquíni, bradava contra o imperialismo, recitava Shakespeare "nei corridoi del Palazzo" e, após sete meses de governo, se demitira $^{42}$. Era assim que João Goulart subira ao poder:

Egli è il "padre degli operai", ama le belle donne, lo Whisky, i cavalli, le mucche, il "chimarro", perché è un "gaucho". Ma è ancora Macunaima. Con Goulart, o "Jango", come lo chiama il popolo, "gli operai, gli studenti, i contadini erano al potere”. L'agitazione politica cresce, il 
paese è dominato da "sovversione e da corruzione", perché Jango come Macunaima, si trova sempre tra Dio e il Diavolo.

Arrivano i militari e cacciano Jango, la politica dei tropici ripete sempre la stessa musica. ${ }^{43}$

Como nos filmes, não é somente o "conteúdo" da fala de Glauber Rocha, a história e a perspectiva ideológica com a qual é narrada, a conferir o sentido da sua visão de mundo, mas é o próprio estilo, a forma com a qual o seu discurso se apresenta, a explicitar a leitura que o cineasta fazia do seu tempo. Neste novo ensaio, a escritura rompe os limites entre o que é pura figuração e o que é a própria realidade, entrelaçando em uma única representação arte e política, História e ficção, heróis nacionais e farsantes eleitos, mitos literários e imaginários cinematográficos. Aspecto incindível da nação, cada elemento encontra-se em um estado de tensão latente, prestes a unir-se com o seu oposto, em uma metamorfose contínua que, exatamente pelo incessante e previsível transformismo, acaba por manifestar-se enquanto elemento unificador da identidade nacional.

Diversamente do discurso de Gênova, embarricado nas trincheiras do confronto, a fala de Glauber revelava agora o estado de transição em que se processavam as aspirações dos intelectuais brasileiros. Tratava-se de compreender e expressar um estágio intermediário, vivido entre a reação imposta pelo Estado e a revolução almejada pela utopia. Elaborada nesta condição de passagem, a forma cinematográfica não podia veicular uma mensagem de senso único, seja porque fosse expressão de uma íntima crise, seja porque estivesse submetida ao veto de um poder centralizado. Era assim, informava o cineasta, que os censores proibiam o explicitamente político Os herdeiros, ao mesmo tempo que aprovavam Macunaíma, viva expressão do inconsciente nacional.

Glauber Rocha citava também Brasil ano 2000, de Walter Lima Jr.; Azyllo muito louco de Nelson Pereira dos Santos e Pindorama, de Arnaldo Jabor. Sendo obras que acompanhavam e expressavam as mudanças ocorridas no país, apresentavam características diversas, em relação às quais ele procurava preparar os receptores europeus. Do mesmo modo que, em 1964, o público e os críticos puderam observar as novidades no cinema brasileiro, "con i film sui negri, sui cangaceiros e sui contadini”, as obras atuais também causariam surpresa, inclusive em relação "allo stesso cinema brasiliano" 4 . Tratava-se de uma nova maneira de ver o Brasil e os brasileiros que se desmarcava de interpretações anteriores, revelando um novo estado de espírito e uma nova consciência de si: "Come Macunaima, noi non abbiamo carattere, ma non vogliamo un
43. Ibidem, p. 465-466.

44. Ibidem, p. 466. 
45. Ibidem.

46. Ibidem. modello di carattere: per lo sviluppo dei tropici si deve prendere il nostro proprio destino e trovare la nostra forma di civiltà" ${ }^{4}$. Apesar de rebater a recusa de um modelo externo para a própria identidade cultural, o ponto de vista não era mais o da oposição absoluta entre "colonizados" e "colonizadores". A leitura tropicalista manifestava-se, então, enquanto consciência do atravessamento de uma fase em que se era e não se era o "outro": "Con questa presentazione di 'Macunaíma' e di 'Gli ereditieri”, concluía o cineasta, "voglio dire al pubblico e ai critici internazionali che noi adesso ci sentiamo uguali, ma anche diversi da voi" 46 . 


\section{Referências}

ANDRADE, Joaquim Pedro de. "Antropofagia e autofagia”. Rivista Ombre Rosse. n. 8, p. 39, dez.1969.

BERNARDET, Jean-Claude. Brasil em tempo de cinema: Ensaio sobre o cinema brasileiro de 1958 a 1966. Rio de Janeiro: Civilização Brasileira, 1967.

CAPDENAC, Michel. "Colloquio con il teorico del cinema nuovo”. Cinema 60. n. 65-66, p. 45-50, 1967.

CARRILHO, Arnaldo. "Técnicas de trabalho e estrutura econômica do Cinema Novo". Terzo Mondo e Comunità Mondiale: Testi delle relazioni presentate e lette ai congressi di Genova. Milão: Editore Marzoratti, 1967, p. 425-428.

DAHL, Gustavo; SARACENI, Paulo Cesar. "Cinema Novo e estruturas econômicas tradicionais”. Terzo Mondo e Comunità Mondiale: Testi delle relazioni presentate e lette ai congressi di Genova. Milão: Editore Marzoratti, 1967, p. 429434.

"Una canaglia in crisi". Rivista Ombre Rosse. n. 8, p. 38 , dez. 1969.

DIEGUES, Carlos. Cinema Brasileiro: Idéias e imagens. Porto Alegre: Editora da Universidade Federal do Rio Grande do Sul, 1999.

."Rapporto dialettico, cinema e cultura in Brasile: Storia e bilancio". Terzo Mondo e Comunità Mondiale: Testi delle relazioni presentate e lette ai congressi di Genova. Milão: Editore Marzoratti, 1967, p. 417-420.

"Un cinema sempre nuovo". Rivista Ombre Rosse. n. 8, p. 32-34, dez. 1969.

FIGUEIRÔA, Alexandre. Cinema Novo: A onda do jovem cinema e sua recepção na França. Campinas: Papirus, 2004.

GALVÃO, Maria Rita. Burguesia e Cinema: O Caso Vera Cruz. Rio de Janeiro: Civilização Brasileira, 1981.

GOMES, Paulo Emílio Salles. "Uma situação colonial?”. Revista Contracampo. ed. 15, mar. 2000. Disponível em: http://www.contracampo.com.br/15/umasituacaocolonial. htm. Acesso em: 16/05/2014.

NEVES, David. "Poética do Cinema Novo". Terzo Mondo e 
Comunità Mondiale: Testi delle relazioni presentate e lette ai congressi di Genova. Milão: Editore Marzoratti, 1967, p. 421423.

ROCHA, Glauber. "Cinema Novo e cinema mondiale”. Terzo Mondo e Comunità Mondiale: Testi delle relazioni presentate e lette ai congressi di Genova. Milão: Editore Marzoratti, 1967, p. 435-436.

. "Eztetyka da fome 65". In: . Revolução do

Cinema Novo. São Paulo: Cosac Naify, 2004. p. 63-67.

. "Il nuovo cinema brasiliano è tropicalista". Rivista

Cineforum. n. 87, p.464-446, set. 1969.

. "L'estetica della violenza". Rivista Cinema 60. n. 51, p. 35-36, mar. 1965.

- Revisão crítica do cinema brasileiro. São Paulo:

Cosac e Naify, 2003.

SALEM, Helena. Nelson Pereira dos Santos: El sueño possible del cine brasileño. Madrid: Ediciones Cátedra, 1997.

VELOSO, Caetano. "Carta a Glauber Rocha, Londres, setembro 1970”. In: BENTES, Ivana (org.). Glauber Rocha: Cartas ao mundo. São Paulo: Companhia das Letras, 1997, p. 373-379.

VIANY, Alex. "Cinema brasiliano ieri e oggi”. Rivista Bianco e Nero. Roma, n. 2, p. 14-43, fev. 1964.

VIGAN , Aldo. "Discorso di Aldo Viganò". Terzo Mondo e Comunità Mondiale: Testi delle relazioni presentate e lette ai congressi di Genova. Milão: Editore Marzoratti, 1967, p. 409410.

\section{Filmografia citada}

Azyllo muito louco. Direção: Nelson Pereira dos

Santos. Brasil: Nelson Pereira dos Santos Produções

Cinematográficas; Luiz Carlos Barreto Produções

Cinematográficas; Produções Cinematográficas R. F. Farias;

Difilm, 1970.

Barravento. Direção: Glauber Rocha. Brasil: Iglu Filmes, 1962. 
Brasil ano 2000. Direção: Walter Lima Jr. Brasil: Mapa Filmes, 1969.

Bravo guerreiro, O. Direção: Gustavo Dahl. Brasil: Gustavo Dahl Produções Cinematográficas, 1969.

Desafio, O. Direção: Paulo Cesar Saraceni. Brasil: Mapa Filmes, 1965.

Deus e o diabo na terra do sol. Direção: Glauber Rocha. Brasil: Copacabana Filmes, 1964.

Dragão da maldade contra o santo guerreiro, $O$. Direção: Glauber Rocha. Brasil/Alemanha Ocidental/Argentina/ Noruega/Suécia, Antoine Films, 1969.

Fuzis, Os. Direção: Ruy Guerra. Brasil/Argentina: Copacabana Filmes, 1964.

Ganga Zumba. Direção: Carlos Diegues. Brasil: Copacabana Filmes, 1963.

Herdeiros, Os. Direção: Carlos Diegues. Brasil: Carlos Diegues Produções Cinematográficas, 1969.

Macunaíma. Direção: Joaquim Pedro de Andrade. Brasil: Condor Filmes, 1969.

Pindorama. Direção: Arnaldo Jabor. Brasil: Kamera Filmes Ltda, 1971.

Rio 40․ Direção: Nelson Pereira dos Santos. Brasil: Equipe Moacyr Fenelon, 1955.

Terra em transe. Direção: Glauber Rocha. Brasil: Mapa Filmes, 1967.

Vidas sêcas. Direção: Nelson Pereira dos Santos. Brasil: Luiz Carlos Barreto Produções Cinematográficas, 1963. 
